\title{
Fifteen countries are at risk of Ebola outbreak, says WHO
}

\author{
Anne Gulland
}

London

The World Health Organization has drawn up a list of 15 countries that are most at risk of an outbreak of Ebola virus disease. The countries have land borders or strong trade and travel routes to the three most affected countries, Guinea, Liberia, and Sierra Leone, and health systems that are not strong enough to cope with a potential outbreak.

The 15 are Mali, Ivory Coast, Senegal, and Guinea-Bissau (the four countries bordering the three affected countries) and Benin, Cameroon, the Central African Republic, the Democratic Republic of Congo, Ghana, South Sudan, Nigeria, Mauritania, Togo, and Burkina Faso.

Isabelle Nuttall, WHO's director of global capacities, alert, and response, told a press conference this week that WHO was working with the 15 countries at risk to help them assess what they have done so far and what is still needed. She said, "This work is not starting today. We have been working with countries for many years to ensure they are better prepared to detect and to respond to any outbreak. Most of these countries have had to deal with outbreaks, and the principles are the same: you must be ready to detect, inform, assess, and respond."

She said WHO would "ramp up" its efforts with these countries, running a simulation exercise to test their response to an outbreak. When asked if she thought that the four bordering countries had undetected or unreported cases of Ebola virus disease, she said that the countries had already been sounding alerts about suspected cases, which provided some level of reassurance.

She added that because healthcare workers had been hit hard in the outbreak, with 427 infected so far and 236 deaths, this group would be a focus of efforts. "We will pay a lot of attention to supporting countries to ensure they have enough personal protection equipment in place and that healthcare workers are trained in how to use the equipment. We have developed a checklist that will help countries going through systematically what they need to have in place.

"Healthcare workers are on the front line-we can never say that enough. They need to be protected."

She also emphasised the importance of tracing of contacts, saying that the success in containing the outbreaks in Senegal and Nigeria was directly linked to this. WHO is due to declare Senegal free of the disease on Friday 17 October and Nigeria on 20 October. The declaration can be made when no new cases have been reported for 42 days.

WHO figures dated 15 October report a total of 8997 cases of Ebola virus disease in west Africa, with 4493 deaths, and a doubling in the number of cases every four weeks. The figures show an increase in incidence in Guinea because of a spike in the capital, Conakry.

In Liberia data gathering is a problem, but there seems to have been a decrease in the number of cases in the northernmost county of Lofa, adjoining Sierra Leone and Guinea. Nuttall said, "This is encouraging since this area was hit hard early on, but we made a concerted effort. Remember, we have had drops [in incidence] before, and then we have seen another increase."

In Sierra Leone the hardest hit area is the capital, Freetown, alongside two other districts.

thebmj.com Feature: Ebola-How well is the UK prepared? (BMJ 2014;349:g6288, doi:10.1136/bmj.g6288)

Cite this as: BMJ 2014;349:96305

๑ BMJ Publishing Group Ltd 2014 